At-Taradhi: Jurnal Studi Ekonomi

Volume XI Nomor 1, Juni 2019

P-ISSN: 1979-3804, E-ISSN: 2548-9941

\title{
Analisis Terhadap Dalil Hukum dalam Fatwa Dewan Syariah Nasional Majelis Ulama Indonesia Nomor 6 Tahun 2000 Tentang Istishna
}

\author{
Noorwahidah Haisyi \\ Dosen Fakultas Ekonomi dan Bisnis Islam Universitas Islam Negeri Antasari. E-mail: \\ wahidah.noor@gmail.com
}

\section{ARTICLE INFO}

Kata Kunci:
Akurasi Dalil; Istishna';
Relevansi Dalil
Cara Sitasi:
Haisyi, Noorwahidah.
"Analisis Terhadap
Dalil Hukum dalam
Fatwa Dewan Syariah
Nasional Majelis
Ulama Indonesia
Nomor 6 Tahun 2000
Tentang Istishna." At-
Taradhi: Jurnal Studi
Ekonomi 10, no. 1
(2019): 25-36.

\section{Pendahuluan}

Jual beli Istishna' adalah salah satu akad dalam transaksi keuangan syariah, yaitu jual beli dalam bentuk pemesanan pembuatan barang tertentu dengan kriteria, persyaratan, dan

\begin{abstract}
The legal basis stated in the Fatwa of the National Sharia Council (DSN)

Number 6 of 2000 concerning Istishna' is very minimal, because it only consists of two hadith, one fiqh rule, and one ijtihad. This research was carried out to assess the accuracy of these four legal bases against the istishna' provisions contained in the fatwa, and to trace other legal bases of the Qur'an and hadith which were deemed more relevant. This is a qualitative research with the library research approach. The legal material studied is the fatwa of DSN No. 6 of 2000 concerning Istishna', as well as legal arguments in the form of the Qur'an and hadith. The findings are then analyzed descriptively. The results of the research show that the legal basis used by the DSN to support istishna' provisions in this fatwa is indeed quite accurate, but there are at least two verses of the Qur'an and two hadiths that are more relevant as the basis of these istishna' legalities.
\end{abstract}

Dasar hukum yang dicantumkan dalam Fatwa Dewan Syariah Nasional (DSN) Nomor 6 Tahun 2000 tentang Istishna' sangat minim, karena hanya terdiri dari dua hadis, satu kaidah fikih, dan satu ijtihad ulama. Maka riset ini dilakukan untuk menilai keakuratan keempat dasar hukum tersebut terhadap ketentuan-ketentuan istishna' yang tercantum dalam fatwa, serta menelusuri dasar hukum lain dari al-Qur'an dan hadis yang dipandang lebih relevan. Penelitian ini merupakan riset kualitatif dengan menggunakan pendekatan kepustakaan (library research). Bahan hukum yang dikaji adalah Fatwa DSN No. 6 Tahun 2000 tentang Istishna, serta dalil hukum dalam bentuk al-Qur'an dan hadis. Sumber kepustakaan tersebut kemudian dianalisa secara deskriptif. Hasil riset menunjukkan bahwa dasar hukum yang digunakan oleh DSN untuk menunjang ketentuanketentuan istishna' dalam fatwa nomor 6 tahun 2000 ini memang cukup akurat, namun ada setidaknya dua ayat al-Qur'an serta dua hadis yang lebih relevan sebagai dasar legalitas istishna' tersebut. 
harga tertentu yang disepakati antara pemesan (pembeli/ mustashni) dan penjual (pembuat, shani). ${ }^{1}$

Hukum istishna' ini sendiri diperdebatkan oleh para ulama. Pendapat pertama menyatakan bahwa istishna' adalah akad yang tidak benar dan batil. Transaksi menggunakan akad istishna' adalah transaksi yang haram dan tidak sah. Pendapat ini dikemukakan oleh mazhab Hambali dan salah seorang ulama terkemuka mazhab Hanafi, Zufar bin al Huzail al 'Anbari (w. $158 \mathrm{H}$ ). Pendapat kedua menyatakan bahwa istishna' adalah salah satu bentuk akad salam. $^{2}$ Akad ini boleh dilakukan dalam bertransaksi asal syarat-syarat yang tertuang di dalam syarat salam terpenuhi. Apabila syarat-syarat salam tidak terpenuhi, maka akad istishna' akan menjadi tidak sah dan batil. Pendapat ini dikemukakan oleh mazhab Maliki \& Syafi'i. Pendapat ketiga menyatakan bahwa istishna' adalah akad yang benar dan halal. Pendapat ini dikemukakan oleh kebanyakan ulama penganut mazhab Hanafi dan kebanyakan fuqaha di dunia modern.

Dewan Syariah Nasional (DSN) Majelis Ulama Indonesia (MUI) menganggap bahwa masyarakat membutuhkan fasilitas pembiayaan berdasarkan prinsip jual beli istishna' ini. Apalagi lembaga keuangan syariah (LKS) pun juga memiliki kepentingan untuk memberikan fasilitas tersebut kepada masyarakat. Mempertimbangkan dua hal ini, DSNMUI menganggap perlu menetapkan fatwa tentang jual beli istishna' agar dalam praktik yang dilakukan oleh masyarakat dan LKS tidak bertentangan dengan prinsip-prinsip syariah. Maka pada tanggal 04 April 2000, bertepatan dengan tanggal 29 Dzulhijjah 1420 hijriah, DSN-MUI mengeluarkan fatwa Nomor 06/DSN-MUI/IV/2000 tentang Jual Beli Istishna'.

Fatwa tersebut pada dasarnya menyatakan bahwa bertransaksi dengan akad istishna' dapat diperbolehkan dengan beberapa persyaratan tertentu, baik syarat terkait dengan pembayaran maupun syarat yang berhubungan dengan barang yang menjadi objek istishna'.

Sebagaimana fatwa-fatwa DSN-MUI yang lain, fatwa tentang istishna' ini disertai dengan beberapa dalil hukum yang menjadi landasan fatwa tersebut. Namun, jika diperhatikan dalildalil yang dijadikan landasan fatwa itu terlihat sangat minim dibanding dengan dalil-dalil hukum yang digunakan untuk transaksi jual beli lainnya (salam dan murabahah).

Dalil yang terdapat dalam fatwa tentang istishna' ini hanya terdiri dari dua buah hadis, satu kaidah fiqhiyah, dan kutipan pendapat mazhab Hanafi yang membolehkan bertransaksi Istishna'. Hal ini berbeda dengan dalil-dalil yang digunakan untuk fatwa tentang salam, dimana DSN-MUI mengemukakan dua ayat suci Alquran (surah al-Baqarah (2) ayat 282 dan Al-Maidah (5) ayat 1), empat buah hadis, ijmak, serta satu kaidah fiqhiyah.

Dalil untuk jual beli murabahah lebih banyak lagi. Fatwa DSN-MUI nomor 04/DSNMUI/IV/2000 tentang Murabahah yang dikeluarkan pada tanggal 26 Dzulhijjah $1420 \mathrm{H}$ (01 Aril 2000) menyebutkan empat ayat suci Alquran dan enam hadis Nabi Muhammad. Keempat ayat tersebut ialah ayat 29 surah An-Nisa (4), ayat 275 surah Al-Baqarah (2), ayat pertama surah Al-Maidah (5), dan ayat 280 surah Al-Baqarah (2). Sedangkan enam hadis yang digunakan sebagai dalil hukum adalah hadis riwayat Al-Baihaqi dan Ibn Majah, Ibn Majah, At-Turmudzi, al-Jamaah, An-Nasa i, Abu Daud, Ibn Majah, dan Ahmad, dan hadis

\footnotetext{
${ }^{1}$ Siti Mujiatun, “Jual Beli Dalam Perspektif Islam: Salam Dan Istisna'," Jurnal Riset Akuntansi Dan Bisnis 13, no. 2 (2013): 212, http://jurnal.umsu.ac.id/index.php/akuntan/article/view/149.

2 Muhammad Maksum, "Penerapan Hukum Jaminan Fidusia Dalam Kontrak Pembiayaan Syariah," Jurnal Cita Hukum 3, no. 1 (2015): 6, http://dx.doi.org/10.15408/jch.v2i1.1837.
} 
riwayat Abd ar-Raziq dari Zaid bin Aslam. Kemudian dikemukakan pula ijmak dan satu kaidah fiqhiyah.

Jika ditinjau dari sisi keakuratan dalil, terlihat bahwa dalil-dalil hukum yang digunakan DSN-MUI untuk fatwa tentang istibsna ' hanyalah dalil yang bersifat umum, tidak ada yang bersifat khusus yang menunjukkan bahwa dalil-dalil tersebut merupakan dalil untuk Istishna'. Meskipun dalil hukum yang digunakan sangat minim, ketentuan dalam fatwa yang dikeluarkan DSN-MUI tentang istishna' ini ternyata cukup banyak. Isi dari fatwa itu meliputi ketentuan tentang pembayaran istishna' sebanyak tiga poin, ketentuan tentang barang sebanyak 7 poin, dan ketentuan lain sebanyak 3 poin. ${ }^{3}$ Kenyataan ini menarik perhatian penulis untuk melakukan penelitian mengenai dalil-dalil yang digunakan DSN-MUI tentang istishna' ini, terutama untuk dua hal: Pertama, terkait dengan akurasi dalil dalam konteks dengan jual beli Istishna' dan kedua, penelusuran terhadap dalil yang lebih relevan dengan isi fatwa.

Sepanjang pengetahuan penulis, riset ini adalah penelitian pertama yang meneliti tentang dalil yang digunakan oleh DSN-MUI dalam fatwa tentang istishna'. Penelitian lainnya lebih banyak membahas mengenai penerapan fatwa tersebut, baik secara formal di lembaga keuangan syariah, maupun secara non-formal sebagaimana dipraktekkan oleh masyarakat.

Liana Nurcahaya Yulianti, Neneng Nurhasanah, dan N. Eva Fauziah menerbitkan riset berjudul "The Implementation of DSN Fatwa Number 06/DSN-MUI/IV/2000 on the Istishna Sale and Purchase on the Implementation of Istishna Agreement of Product KPR Indent IB in BTN Syariah Branch Bandung." Mereka menemukan bahwa produk istishna milik Bank Tabungan Negara Syariah Cabang Bandung secara praktek sudah memenuhi ketentuan-ketentuan yang diatur dalam fatwa DSN tentang istishna', kecuali ketentuan pembayaran yang hanya dilakukan dengan menggunakan uang, sedangkan fatwa DSN-MUI memperbolehkan menggunakan alat tukar lain selain uang. ${ }^{4}$

Siti Nurizta menerbitkan riset serupa berjudul "Pelaksanaan Jual Beli Buah-Buahan Petian di Pasar Induk Gede Bage Bandung menurut Fatwa DSN No.06 DSN-MUI/IV/2000 tentang Jual Beli Istishna", yang meneliti pelaksanaan akad istishna' sebagaimana dipraktekkan oleh masyarakat di Pasar Induk Gede Bage Bandung. praktek tersebut sebagian besar sudah memenuhi ketentuan fatwa DSN, namun sayangnya penjual masih belum menjelaskan spesifikasi barang yang menjadi objek istishna' secara detail kepada pembeli. $^{5}$

\footnotetext{
${ }^{3}$ Nur Fathoni, "Konsep Jual Beli dalam Fatwa DSN-MUI," Economica: Jurnal Ekonomi Islam 4, no. 1 (31 Mei 2013): 69, https://doi.org/10.21580/economica.2013.4.1.773.

${ }^{4}$ Liana Nurcahaya Yulianti, Neneng Nurhasanah, dan N. Eva Fauziah, "The Implementation of DSN Fatwa Number 06/DSN-MUI/IV/2000 on the Istishna Sale and Purchase on the Implementation of Istishna Agreement of Product KPR Indent IB in BTN Syariah Branch Bandung," dalam Prosiding Hukum Ekonomi Syariah (Bandung: Universitas Islam Bandung, 2016), 191, http://karyailmiah.unisba.ac.id/index.php/hukum_ekonomi_syariah/article/view/2425.

5 Siti Nurizta, "Pelaksanaan Jual Beli Buah-Buahan Petian di Pasar Induk Gede Bage Bandung menurut Fatwa DSN No.06 DSN-MUI/IV/2000 tentang Jual Beli Istishna” (Universitas Islam Negeri Sunan Gunung Djati, 2018), http://digilib.uinsgd.ac.id/13821/.
} 
Similar dengan penelitian Siti Nurizta di atas, Zainal Musthofa melakukan analisa terhadap praktek akad istishna' dalam produk kerajinan. Ketidaksesuaian dengan fatwa pun juga terletak pada spesifikasi barang yang tidak disebutkan secara rinci oleh penjual. ${ }^{6}$

Dari pemaparam di atas maka peneliti tertarik mengangkat masalah penelitian yang berjudul "Analisis terhadap Dalil Hukum dalam Fatwa Dewan Syariah Nasional Majelis Ulama Indonesia Nomor 6 Tahun 2000 tentang Istishna".

\section{Isi Fatwa DSN-MUI tentang Istishna'}

Fatwa DSN-MUI tentang istishna' terdiri dari klausul pertimbangan yang berisi latar belakang mengapa dibutuhkan fatwa tersebut dan dasar pelaksanaan kegiatan yang sudah dipraktekkan oleh lembaga keuangan syariah. Klausul ini terdiri atas tiga poin. Poin pertama berisi penegasan bahwa masyarakat memerlukan transaksi dalam bentuk istishna'. Poin pertama ini lengkapnya berbunyi:

bahwa kebutuhan masyarakat untuk memperoleh sesuatu, sering memerlukan pihak lain untuk membuatkannya, dan hal seperti itu dapat dilakukan melalui jual beli Istishna' (الاستصناع), yaitu akad jual beli dalam bentuk pemesanan pembuatan barang tertentu dengan kriteria dan persyaratan tertentu yang disepakati antara pemesan (pembeli, mustashni') dan penjual (pembuat, shani');

Poin kedua menegaskan bahwa pada kenyataannya transaksi istishna' sudah dilakukan oleh lembaga keuangan syariah. Ini menunjukkan bahwa sebelum ada fatwa DSN-MUI tentang istishna' dalam praktek lebaga keuangan syariah transaksi dengan menggunakan akad istishna' ini sudah terjadi. Selanjutnya pada poin ketiga dari klausul pertimbangan ini ditegaskan bahwa kebutuhan akan fatwa DSN-MUI sangat diperlukan untuk menjadi pedoman bagi lembaga keuangan syariah agar praktek-praktek istishna' yang dilakukan tidak menyimpang dari prinsip-prinsip syariah.

Struktur berikutnya adalah klausul mengingat yang berisi dalil-dalil yang menjadi dasar hukum istishna' tersebut. Seperti dikemukakan terdahulu, landasan hukum yang digunakan ada dua hadis, satu kaidah fikih, dan satu pendapat mazhab Hanafi yang berpendapat bahwa istishna' boleh dilakukan dalam transaksi.

Hadis pertama adalah hadis riwayat Imam at-Turmudzi dari Amr bin `Auf:

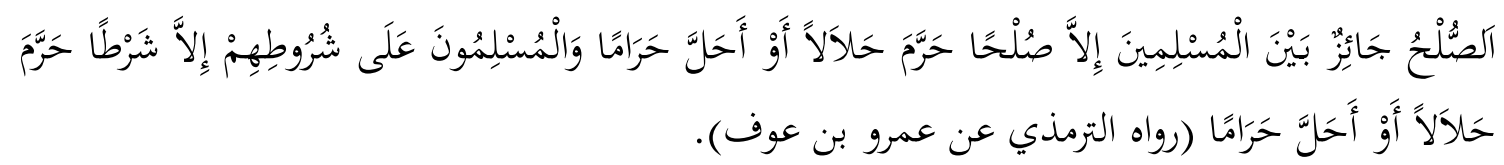

Artinya: "Perdamaian dapat dilakukan di antara kaum muslimin kecuali perdamaian yang mengharamkan yang halal atau menghalalkan yang haram; dan kaum muslimin terikat dengan syarat-syarat mereka kecuali syarat yang mengharamkan yang halal atau menghalalkan yang haram” (HR. Tirmizi dari 'Amr bin 'Auf).

Hadis kedua adalah hadis riwayat Ibn Majah dan ad-Dar al-Quthni, dari Abu Sa`id alKhudhri:

\footnotetext{
${ }^{6}$ Zainal Musthofa, “Analisis Terhadap Praktik Jual Beli Istishna' Pada Produk Kerajinan Berdasarkan Fatwa Dewan Syariah Nasional No: 06/DSN-MUI/IV/2000 (Studi Kasus Di Sentra Kerajinan Kasongan Daerah Istimewa Yogyakarta)" (Universitas Muhammadiyah Yogyakarta, 2017), http:// repository.umy.ac.id/handle/123456789/21816.
} 


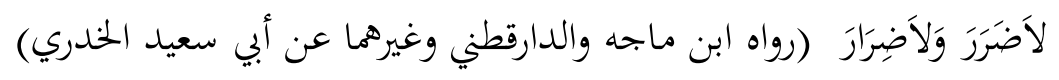

Artinya: "Tidak boleh membahayakan diri sendiri maupun orang lain" (HR, Ibnu Majah, Daraquthni, dan yang lain dari Abu Sa’id al-Khudri).

Dalil hukum berupa hadis di atas kemudian diikuti oleh kaidah fikih. Kaidah fikih sendiri sebenarnya bukanlah merupakan dalil hukum, melainkan suatu pedoman yang memudahkan para mujtahid untuk melakukan istinbath hukum. ${ }^{7}$ Kaidah fikih yang digunakan di dalam fatwa DSN-MUI tentang istishna' ini berbunyi:

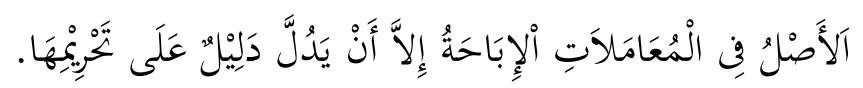

Artinya: "Pada dasarnya, semua bentuk muamalah boleh dilakukan kecuali ada dalil yang mengharamkannya."

Klaulus mengingat ini diakhiri dengan pemuatan pendapat mazhab Hanafi yang mengatakan bahwa istishna' hukumnya boleh (jawaz) karena hal itu telah dilakukan oleh masyarakat muslim sejak masa awal tanpa ada pihak (ulama) yang mengingkarinya.

Berikutnya yaitu klausul memperhatikan yang berisi pendapat peserta Rapat Pleno Dewan Syariah Nasional pada hari Selasa, tanggal 29 Dzulhijjah 1420 H./4 April 2000.

Fatwa ini kemudian diakhiri dengan batang tubuh keputusan yang isi selengkapnya yaitu sebagai berikut:

Pertama: Ketentuan tentang Pembayaran:

1. Alat bayar harus diketahui jumlah dan bentuknya, baik berupa uang, barang, atau manfaat.

2. Pembayaran dilakukan sesuai dengan kesepakatan.

3. Pembayaran tidak boleh dalam bentuk pembebasan butang.

Kedua: Ketentuan tentang Barang:

1. Harus jelas ciri-ciriny a dan dapat diakui sebagai butang.

2. Harus dapat dijelaskan spesifikeasinya.

3. Penyerahannya dilakukan kemudian.

4. Waktu dan tempat penyerahan barang harus ditetapkan berdasarkan kesepakatan.

5. Pembeli (pembeli, mustashni') tidak boleh menjual barang sebelum menerimanya.

6. Tidak boleh menukar barang, kecuali dengan barang sejenis sesuai kesepakatan.

7. Dalam hal terdapat cacat atau barang tidak sesuai dengan kesepakatan, pemesan memiliki hak khiyar (hak memilih) untuk melanjutkan atau membatalkan akad.

Ketiga: Ketentuan Lain:

1. Dalam halpesanan sudah dikerjakan sesuai dengan kesepakatan, bukumnya mengikat.

2. Semua ketentuan dalam jual beli salam yang tidak disebutkan di atas berlaku pula pada jual beli istishna'.

3. Jika salah satu pihak tidak menunaikan kewajibannya atau jika terjadi perselisihan di antara kedua belah pihak, maka penyelesaiannya dilakukan melalui Badan Arbitrase Syariah setelab tidak tercapai kesepakatan melalui musyawarah.

Fatwa tersebut ditetapkan di Jakarta pada tanggal 29 Dzulhijjah 1420 H (4 April 2000 M), ditandatangai oleh Ketua, Prof. K.H. Ali Yafie dan Sekretaris, Drs. H.A. Nazri Adlani.

\footnotetext{
7 Parman Komarudin dan Muhammad Rifqi Hidayat, "Konsekuensi Perbedaan Fikih Terhadap Kaidah Fikih," Al-Falah: Jurnal Ilmiah Keislaman Dan Kemasyarakatan 19, no. 1 (2019): 126, http:/ / ejurnal.staialfalahbjb.ac.id/index.php/alfalahjikk/article/view/107.
} 


\section{Metode Penelitian}

Ketiga penelitian di atas hanya meneliti tentang penerapan fatwa istishna' di lapangan, sedangkan objek yang menjadi fokus riset penulis disini adalah dalil-dalil yang dipakai oleh fatwa istishna' itu tersebut.

Penelitian ini merupakan riset kualitatif yang menggunakan pendekatan kepustakaan (library research), yaitu studi penelaahan terhadap buku-buku, literatur-literatur, catatan-catatan, dan laporan-laporan yang ada hubungannya dengan masalah yang diteliti. ${ }^{8}$ Bahan hukum yang menjadi data primer dalam penelitian ini adalah Fatwa DSN No. 6 Tahun 2000 tentang Istishna', serta dalil hukum dalam bentuk al-Qur'an dan hadis yang relevan.

Hasil penelusuran terhadap sumber kepustakaan tersebut selanjutnya dianalisa secara deskriptif, untuk menggambarkan bagaimana tingkat keakuratan dalil hukum yang digunakan oleh DSN-MUI dalam fatwa tentang istishna', serta apa saja dalil lain yang lebih relevan dengan isi fatwa.

\section{Temuan dan Analisis}

Terdapat dua hadis yang digunakan oleh DSN-MUI sebagai landasan hukum untuk menetapkan fatwa tentang jual beli istishna'. Hadis pertama adalah hadis riwayat Imam AtTurmudzi. Hadis ini tidak secara eksplisit berbicara tentang jual beli istishna'. Abu Isa mengatakan bahwa hadis ini adalah hadis Hasan Shahih. Beberapa ahli hadis bahkan menyebutkan bahwa hadis ini juga berstatus shahih. Maka jika ditinjau dari sudut akurasi hadis sebagai landasan hukum, hadis ini sudah memenehi syarat untuk dijadikan hujjah hukum.

Hadis ini banyak digunakan oleh DSN-MUI sebagai dasar dalam pengambilan keputusan. Selain fatwa tentang Istishna Nomor 06/DSN-MUI/IV/2000, hadis ini dipakai juga dalam fatwa DSMN MUI tentang Musyarakah Mutanaqisah Nomor 73/DSN-MUI/XI/2008, fatwa tentang Musyarakah Nomor 08/DSN-MUI/IV/2000, fatwa tentang Potongan Tagihan Murabahah Nomor 46/DSN/MUI/II/2005 serta dalam banyak fatwa DSN-MUI lainnya.

Isi hadis tersebut membicarakan tentang kebolehan melakukan perdamaian di antara kaum muslimin dalam hal yang tidak menghalalkan yang haram atau mengharamkan yang halal. Katentuan ini merupakan rambu-rambu yang harus dipatuhi oleh setiap muslim, bahwa transaksi yang dibenarkan dalam Islam adalah transaksi yang halal lagi baik; tidak ada kebatilan; tidak berlebih-lebihan atau melampaui batas; tidak ada kezaliman, tidak ada unsur riba, maisir (perjudian), dan gharar (ketidakjelasan), serta tidak melupakan tanggung jawab sosial berupa zakat, infaq dan sedekah. ${ }^{10}$

\footnotetext{
8 Arifa Ainun Rondiyah, Nugraheni Eko Wardani, dan Kundharu Saddhono, "Pembelajaran Sastra Melalui Bahasa Dan Budaya Untuk Meningkatkan Pendidikan Karakter Kebangsaan Di Era MEA (Masayarakat Ekonomi Asean)," dalam Proceedings Education and Language International Conference (Semarang: Universitas Islam Sultan Agung, 2017), 142, http://jurnal.unissula.ac.id/index.php/ELIC/article/view/1230.

${ }^{9}$ Lihat lebih lengkap daftar Fatwa-Fatwa DSN MUI dalam Ahmad Ifham Sholihin, Pedoman Umum Lembaga Keuangan Syariah (Jakarta: Gramedia, 2013).

${ }^{10}$ M. Syafi'i Antonio, Bank Syariah: dari Teori ke Praktik (Jakarta: Gema Insani, 2009), 12.
} 
Hadis kedua yang digunakan oleh DSN-MUI adalah hadis riwayat Ibn Majah, ad-Dar alQuthni, dan lain-lain, dari Abu Sa'id al-Khudriy. Hadis ini memiliki beberapa penguat dari sejumlah sahabat lain, diantaranya Ubadah bin Shamit (Ibnu Majah, no. 2340), Abdullah bin Abbas (Ibnu Majah, no. 2341), Abu Hurairah, Jabir bin Abdullah,Tsa'labah bin Abi Malik al-Qurazhi, Abu Lubabah, dan 'Aisyah. Hadis ini dinilai hasan oleh an-Nawawi dalam al-Arba’in, Ibnu Rajab dalam Jami’ul Ulum wa al-Hikam, Syaikh al-Albani dalam Silsilah Ahadits Shahihah (no. 250), Irwa-ul Galil (no. 896), dan Shahih Kitabil Adzkar wa Dha'ifuhu (II/985, no. 981/1247). Maka hadis ini termasuk dalam kategori hadis shahih yang dapat dijadikan hujjah.

Secara umum hadis ini melarang perbuatan darar, ${ }^{11}$ yaitu segala perbuatan yang mendatangkan bahaya atau kerugian, ${ }^{12}$ ataupun membalasnya dengan bahaya atau kerugian yang serupa juga, apalagi dengan yang lebih besar dari bahaya yang menimpanya.

Jika dilihat dari struktur dalil hukum, tampak bahwa kedua hadis diatas ditempatkan di urutan pertama dan kedua. Artinya kedua hadis tersebut merupakan dalil hukum utama kebolehan istishna' di dalam fatwa DSN-MUI. Padahal kedua hadis ini tidak spesifik menunjukkan kepada jual beli istishna. Hadis ini bersifat umum, bahkan sangat umum untuk semua transaksi.

Kaidah fikih yang digunakan di dalam fatwa DSN MUI tentang istishna adalah kaidah umum mengenai muamalah, bahwa setiap bentuk muamalah dihukumi mubah selama tidak ada dalil lain yang melarangnya. ${ }^{13}$ Kaidah ini memiliki makna yang sangat besar dalam kehidupan manusia, bahwa manusia dibebaskan untuk melakukan apa saja dalam hidupnya baik dalam perdagangan, politik, pendidikan, militer, keluarga, dan semisalnya, selama tidak ada dalil yang mengharamkan, melarang, dan mencelanya, maka selama itu pula boleh saja untuk dilakukan. Tak seorang pun berhak melarang dan mencegah tanpa dalil syara' yang menerangkan larangan tersebut. Bahwa apa yang telah dihalalkan oleh Allah maka halal hukumnya, dan apa yang telah diharamkan oleh Allah maka haram hukumnya. Sedangkan sesuatu yang didiamkan berarti dimaafkan dan boleh dilakukan. ${ }^{14}$

Sumber kaidah fikih ini antara lain adalah firman Allah dalam surah al-Baqarah ayat 29 yang berbunyi:

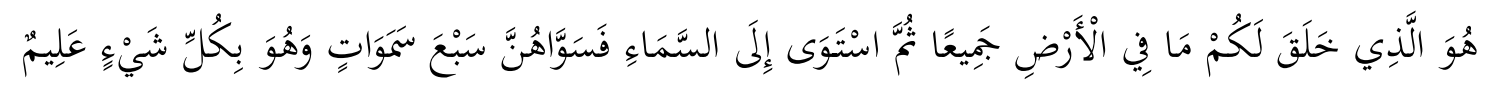

Artinya: "Dia-lah Allah, yang menjadikan segala yang ada di bumi untuk kamu dan Dia berkehendak menuju langit, lalu dijadikan-Nya tujub langit. Dan Dia Maha Mengetahui segala sesuatu."

Allah menyatakan dalam ayat ini bahwa segala sesuatu yang ada di bumi yang diciptakanNya diperuntukkan buat manusia. Dengan demikian pada dasarnya segala sesuatu yang ada

\footnotetext{
${ }^{11}$ Hengki Firmanda, "Hakikat Ganti Rugi Dalam Perspektif Hukum Ekonomi Syariah Dan Hukum Perdata Indonesia,” Jurnal Hukum Respublica 16, no. 2 (2017): 242, https://doi.org/10.31849/respublica.v16i2.1438.

12 Hamdan Al-Jahdali dkk., "Advance Medical Directives: a Proposed New Approach and Terminology from an Islamic Perspective," Medicine, Health Care and Philosophy 16, no. 2 (2013): 166, https://doi.org/10.1007/s11019-012-9382-z.

13 Muhammad Rifqi Hidayat, “Analisis Fikih Klasik Terhadap Badan Hukum Sebagai Aqid,” Al-Iqtishadiyah: Ekonomi Syariah Dan Hukum Ekonomi Syariah 2, no. 2 (2015): 58-59, https://ojs.uniskabjm.ac.id/index.php/IQT/article/view/379.

${ }^{14}$ Amrul Muttaqin, “Transaksi Derivatif Di Lembaga Keuangan Syariah,” UNIVERSUM 9, no. 1 (2015): 20, https://doi.org/10.30762/universum.v9i1.69.
} 
di bumi ini boleh dilakukan dan dimanfaatkan kecuali ada larangan syara', baik eksplisit maupun implisit, yang melarang melakukan perbuatan tersebut.

Kaidah ini sangat kuat kedudukannya dan disepakati oleh para ulama sebagai kaidah umum tentang muamalat. Maka sangat beralasan jika kaidah ini dijadikan DSN-MUI sebagai landasan penetapan fatwa tentang istishna'. Meskipun demikian, sebagaimana terlihat dari bunyi, makna, dan maksud kaidah di atas, kaidah ini tidak menjurus kepada istishna' semata, tetapi betul-betul sangat umum berlaku untuk semua kegiatan muamalat. ${ }^{15}$

Dalil keempat yang dijadikan landasan DSN-MUI untuk menetapkan fatwa kebolehan melakukan akad istishna' dalam jual beli adalah pendapat mazhab Hanafi, yang berpandangan bahwa akad istishna' mutlak diperbolehkan karena ia merupakan akad yang sah dan halal. Pengambilan pendapat mazhab Hanafi sebagai dasar penetapan fatwa DSNMUI dapat dibenarkan, apalagi mazhab ini juga merupakan salah satu mazhab dalam $A b l$ as-Sunnah wa al-Jamaah, sekalipun mayoritas masyarakat muslim di Indonesia menganut mazhab Syafi'i. ${ }^{16}$

Keempat dalil hukum dan landasan yang dijadikan acuan dalam penetapan fatwa DSNMUI tentang istishna' diatas secara kuantitas sangat minim, dan semuanya bersifat umum tanpa ada satu dalil pun yang spesifik atau mendekati spesifikasi membahas mengenai istishna'. Padahal ketentuan yang diatur dalam fatwa tersebut cukup banyak, sehinga harus dikategorikan menjadi tiga bagian yang terdiri dari: ketentuan tentang pembayaran berisi tiga poin; ketentuan tentang barang berisi tujuh poin, dan; ketentuan lain berisi tiga poin.

Memang jika ditinjau dari sudut pandang relevansi, bahwa dengan dalil hukum yang umum, ditambah dengan kaidah fiqhiyah yang juga bersifat umum, serta pendapat mazhab Hanafi mengenai kebolehan istishna', cukup relevan dengan poin-poin isi fatwa tersebut karena keumumannya. Hanya saja akan lebih ideal jika setiap ketentuan dalam fatwa didukung oleh suatu rujukan yang menjadi landasan hukumnya.

Beberapa literatur juga menyebutkan beberapa dalil yang menjadi dasar istishna', namun tidak dicantumkan oleh DSN-MUI dalam fatwanya. Fatwa yang dikeluarkan oleh Majelis Fatwa Dubai sebagaimana disebutkan oleh Islamic Affairs \& Charitable Activities Departement Dubai Arsip Fatwa Nomor 29140 menyebutkan bahwa kebolehan Jual Beli Istishna dapat menggunakan dalil Surah al-Kahfi ayat 94-95 yang berbunyi:

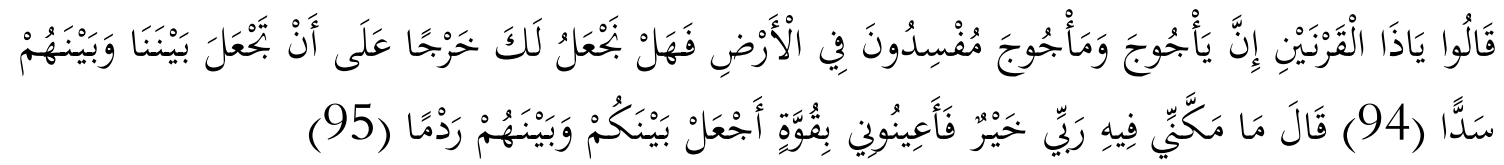

Artinya: "Mereka berkata: "Hai Dzulqarnain, sesunggubnya Yajuj dan Ma'juj itu orang-orang yang membuat kerusakan di muka bumi, maka dapatkah kami memberikan sesuatu pembayaran kepadamu, supaya kamu membuat dinding antara kami dan mereka?" (94) Dzulqarnain berkata: "Apa yang telah dikuasakan oleh Tuhanku kepadaku terhadapnya adalah lebih baik, maka tolonglah aku dengan kekuatan (manusia dan alat-alat), agar aku membuatkan dinding antara kamu dan mereka, (95)

\footnotetext{
15 M. Muamar, "Urgensi Kaidah Fikih dalam Penetapan Fatwa DSN MUI Tahun 2014-2016” (Universitas Islam Negeri Sunan Kalijaga, 2018), 8, http://digilib.uin-suka.ac.id/31144/.

16 Muhammad Maksum, "Kedudukan Syariah sebagai Sumber Hukum Positif: Kajian Awal Atas Hukum Perkawinan, Ekonomi Islam, dan Hukum Ketenagakerjaan di Indonesia dan Maroko," Istinbath: Jurnal Hukum Islam 15, no. 2 (2016): 287.
} 
Ibnu Abbas menyebutkan bahwa makna “خرجاً" adalah "Pahala yang besar”, jual beli istisna' dikategorikan sebagai pahala yang besar karena dapat membantu pembuat dan pemesan. Tidak dapat dipungkiri bahwa mempermudah urusan adalah salah satu tujuan dari syariat ${ }^{17}$ sehingga perlu dijaga kemaslahatannya selama tidak ada dalil yang menentang.

DSN-MUI menggunakan dalil dari kaidah fiqhiyah yang menyebutkan asal dari jual beli adalah halal dalam fatwa istishna' ini, maka seharusnya fatwa dapat merujuk terlebih dahulu dalil dari Alquran yang dapat digunakan adalah dalil umum tentang kehalalan jual beli. Misalnya, firman Allah dalam surah al-Baqarah ayat 275:

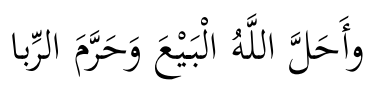

Artinya: "Allah telab menghalalkan jual-beli dan mengharamkan riba."

Ayat ini menjadi alasan para ulama yang menyatakan bahwa hukum asal setiap perniagaan adalah halal, kecuali yang nyata-nyata diharamkan dalam dalil yang kuat dan shahih. ${ }^{18}$

Abu Zaid menyebutkan dalam buku Bahst Aqd al-Istishna' mengenai beberapa dalil lain yang membolehkan akan istishna' yaitu apa yang telah diriwayatkan oleh Imam Bukhari dari hadis Abdullah bin Umar dengan matan sebagai berikut:

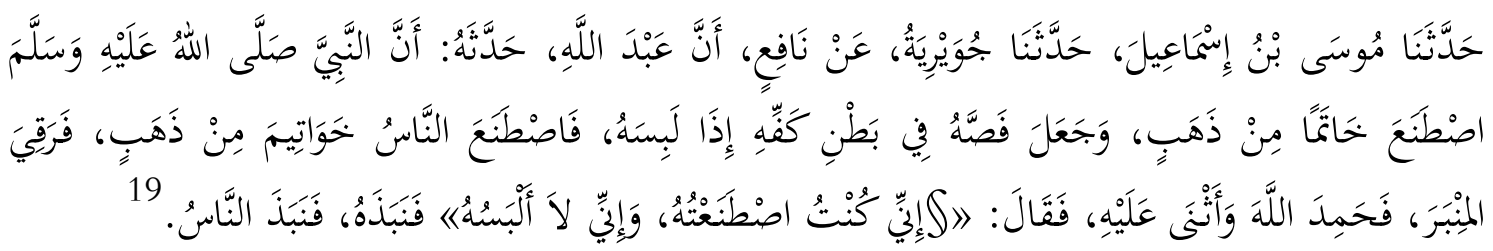

Konteks hadis diatas banyak dipakai oleh ulama sebagai keharaman menggunakan emas oleh laki-laki, namun penjelasan hadis terhadap redaksional "isthashna' $a$ " tidak dipakai oleh para ulama sebagai dalil jual beli istishna'. Abu Zaid menjelaskan bahwa kalimat "isthashna'a" dalam hadis diatas dapat dimaknai sebagai disyariatkannya istishna'.

Abu Zaid menyatakan bahwa dari hadis di atas, Nabi melakukan akad isitshna' sebuah cincin dari emas. Cincin tersebut kemudian dibuang oleh Nabi karena terbuat dari emas yang diharamkan bagi laki-laki untuk berhias dengannya.

Peristiwa serupa disebutkan dalam riwayat lain sebagai berikut:

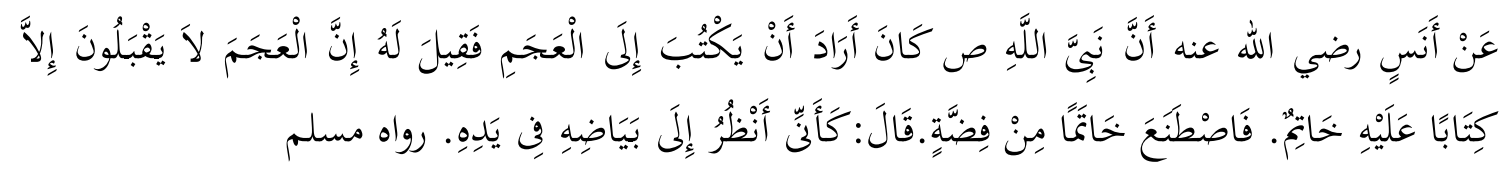

Artinya: "Dari Anas RA bahwa Nabi SAW hendak menuliskan surat kepada raja non-Arab, lalu dikabarkan kepada beliau bahwa raja-raja non-Arab tidak sudi menerima surat yang tidak distempel. Maka beliau pun memesan agar ia dibuatkan cincin stempel dari bahan perak.

\footnotetext{
${ }^{17}$ Ah Azharuddin Lathif, "Konsep Dan Aplikasi Akad Murabahah Pada Perbankan Syariah Di Indonesia," $\begin{array}{lllllll}\text { AHKAM : Jurnal Ilmu Syariab } & \text { 12, } & \text { no. } & 2012): & 72 \text {, }\end{array}$ http://journal.uinjkt.ac.id/index.php/ahkam/article/view/967.

${ }^{18}$ Eka Sari Ulya, “Analisis Hukum Islam Terhadap Perubahan Harga Pada Tebasan Padi Yang Belum Panen Di Desa Betiring Kecamatan Brondong Kabupaten Lamongan” (Universitas Islam Negeri Sunan Ampel, 2015), 35, http://digilib.uinsby.ac.id/2239/.

${ }^{19}$ Muhammad bin Ismail al-Bukhari, Shahih Bukhari, vol. 7 (Mesir: al-Matba'ah al-Kubra al-Amiriyyah, 1312), 157.
} 
Anas mengisabkan: Seakan-akan sekarang ini aku dapat menyaksikan kemilau putih di tangan beliau." (HR. Muslim) ${ }^{20}$

Sebagian fuqaha kontemporer berpendapat bahwa jual beli istishna' adalah sah atas dasar qiyas dan aturan umum syariah ${ }^{21}$ karena itu memang jual beli biasa dan si penjual akan mampu mengadakan barang tersebut pada saat penyerahan. Demikian juga terjadinya kemungkinan perselisihan atas jenis dan kualitas suatu barang dapat di minimalkan dengan pencantuman spesifikasi dan ukuran-ukuran serta bahan material pembuatan barang tersebut.

Dua dalil dari Alquran dan dua dari hadis di atas memungkinkan untuk menjadi dalil bagi istishna' yang belum tercantum dalam fatwa DSN-MUI.

\section{Penutup}

\subsection{Kesimpulan}

Kedua hadis dan kaidah fikih yang dicantumkan DSN-MUI dalam fatwa tentang istishna' bersifat sangat umum, yang memberikan legalitas terhadap seluruh bentuk transaksi muamalah selama tidak ada dalil lain yang mengharamkan, sehingga dapat dianggap cukup akurat terhadap ketentuan-ketentuan istishna' yang terdapat dalam fatwa tersebut. Hanya saja masih ada dua ayat al-Qur'an dan dua hadis yang seharusnya lebih tepat dibandingkan dasar hukum yang dicantumkan DSN-MUI, yaitu surah al-Kahfi ayat 94-95 yang mengisahkan tentang pembangunan dinding oleh Dzu al-Qarnain, surah al-Baqarah ayat 275 tentang kehalalan jual-beli, serta dua hadis riwayat Imam Bukhari tentang pembuatan cincin dari emas dan perak.

Penelitian ini hanya terbatas kepada penelusuran dalil-dalil yang memberikan legalitas praktek jual-beli istishna' semata, tanpa menelusuri dalil-dalil yang dapat menjadi dasar terhadap 13 ketentuan istishna' yang dirumuskan DSN-MUI. Maka riset berikutnya yang melakukan penelusuran terhadap hal tersebut perlu dilakukan. Selain itu, dasar hukum yang terdapat dalam fatwa DSN-MUI nomor 22 tahun 2002 tentang Istishna' Paralel juga menarik untuk dikaji, apalagi akad istishna paralel ini merupakan turunan dari akad istishna' tersebut.

\subsection{Saran}

a. Diharapkan penelitian ini dapat memberikan legalitas dalam praktek jual beli istishna dan untuk pengembangan riset selanjutnya

b. Dasar hukum yang terdapat dalam fatwa DSN-MUI nomor 22 tahun 2002 tentang Istishna' Paralel juga dapat dikaji atau dilakukan penelitian.

\section{Daftar Pustaka}

Ah Azharuddin Lathif. "Konsep Dan Aplikasi Akad Murabahah Pada Perbankan Syariah Di Indonesia." AHKAM: Jurnal Ilmu Syariah 12, no. 2 (2012). http://journal.uinjkt.ac.id/index.php/ahkam/article/view/967.

\footnotetext{
${ }^{20}$ Muslim bin Hajjaj, Sabih Muslim (Beirut: Dar al-Kutub al-Ilmiyah, 1991), 1657.

21 Rubiati Ningsih, "Analisis Akad Jual Beli Tidak Cash Dalam Perspektif Hukum Islam (Studi Kasus Mahasiswa Unisba Fak. Syari'ah Angkatan 2009)” (Universitas Islam Bandung, 2014), 36, http://repository.unisba.ac.id:8080/xmlui/handle/123456789/4814.
} 
Al-Jahdali, Hamdan, Salim Baharoon, Abdullah Al Sayyari, dan Ghiath Al-Ahmad. "Advance Medical Directives: a Proposed New Approach and Terminology from an Islamic Perspective." Medicine, Health Care and Philosophy 16, no. 2 (2013). https://doi.org/10.1007/s11019-012-9382-z.

Antonio, M. Syafi'i. Bank Syariah: dari Teori ke Praktik. Jakarta: Gema Insani, 2009.

Fathoni, Nur. "Konsep Jual Beli dalam Fatwa DSN-MUI." Economica: Jurnal Ekonomi Islam 4, no. 1 (31 Mei 2013). https://doi.org/10.21580/economica.2013.4.1.773.

Firmanda, Hengki. "Hakikat Ganti Rugi Dalam Perspektif Hukum Ekonomi Syariah Dan Hukum Perdata Indonesia." Jurnal Hukum Respublica 16, no. 2 (2017). https://doi.org/10.31849/respublica.v16i2.1438.

Hidayat, Muhammad Rifqi. "Analisis Fikih Klasik Terhadap Badan Hukum Sebagai Aqid." Al-Iqtishadiyah: Ekonomi Syariah Dan Hukum Ekonomi Syariah 2, no. 2 (2015). https://ojs.uniska-bjm.ac.id/index.php/IQT/article/view/379.

Komarudin, Parman, dan Muhammad Rifqi Hidayat. "Konsekuensi Perbedaan Fikih Terhadap Kaidah Fikih." Al-Falah: Jurnal Ilmiah Keislaman Dan Kemasyarakatan 19, no.

http://ejurnal.staialfalahbjb.ac.id/index.php/alfalahjikk/article/view/107.

Liana Nurcahaya Yulianti, Neneng Nurhasanah, dan N. Eva Fauziah. "The Implementation of DSN Fatwa Number 06/DSN-MUI/IV/2000 on the Istishna Sale and Purchase on the Implementation of Istishna Agreement of Product KPR Indent IB in BTN Syariah Branch Bandung." Dalam Prosiding Hukum Ekonomi Syariah. Bandung: Universitas Islam Bandung, 2016. http://karyailmiah.unisba.ac.id/index.php/hukum_ekonomi_syariah/article/view/ 2425.

M. Muamar. "Urgensi Kaidah Fikih dalam Penetapan Fatwa DSN MUI Tahun 2014-2016." Universitas Islam Negeri Sunan Kalijaga, 2018. http://digilib.uinsuka.ac.id/31144/.

Maksum, Muhammad. "Kedudukan Syariah sebagai Sumber Hukum Positif: Kajian Awal Atas Hukum Perkawinan, Ekonomi Islam, dan Hukum Ketenagakerjaan di Indonesia dan Maroko." Istinbath: Jurnal Hukum Islam 15, no. 2 (2016): 281-95.

Muhammad bin Ismail al-Bukhari. Shabih Bukhari. Vol. 7. Mesir: al-Matba'ah al-Kubra alAmiriyyah, 1312.

Muhammad Maksum. "Penerapan Hukum Jaminan Fidusia Dalam Kontrak Pembiayaan Syariah." Jurnal Cita Hukum 3, no. 1 (2015). http://dx.doi.org/10.15408/jch.v2i1.1837.

Muslim bin Hajjaj. Sabih Muslim. Beirut: Dar al-Kutub al-Ilmiyah, 1991.

Muttaqin, Amrul. “Transaksi Derivatif Di Lembaga Keuangan Syariah.” UNIVERSUM 9, no. 1 (2015). https://doi.org/10.30762/universum.v9i1.69.

Ningsih, Rubiati. "Analisis Akad Jual Beli Tidak Cash Dalam Perspektif Hukum Islam (Studi Kasus Mahasiswa Unisba Fak. Syari'ah Angkatan 2009).” Universitas Islam Bandung, 2014. http://repository.unisba.ac.id:8080/xmlui/handle/123456789/4814. 
Rondiyah, Arifa Ainun, Nugraheni Eko Wardani, dan Kundharu Saddhono. "Pembelajaran Sastra Melalui Bahasa Dan Budaya Untuk Meningkatkan Pendidikan Karakter Kebangsaan Di Era MEA (Masayarakat Ekonomi Asean)." Dalam Proceedings Education and Language International Conference. Semarang: Universitas Islam Sultan Agung, 2017. http://jurnal.unissula.ac.id/index.php/ELIC/article/view/1230.

Sholihin, Ahmad Ifham. Pedoman Umum Lembaga Kenangan Syariah. Jakarta: Gramedia, 2013.

Siti Mujiatun. "Jual Beli Dalam Perspektif Islam: Salam Dan Istisna'.” Jurnal Riset Akuntansi Dan Bisnis 13, no. 2 http://jurnal.umsu.ac.id/index.php/akuntan/article/view/149.

(2013).

Siti Nurizta. "Pelaksanaan Jual Beli Buah-Buahan Petian di Pasar Induk Gede Bage Bandung menurut Fatwa DSN No.06 DSN-MUI/IV/2000 tentang Jual Beli Istishna." Universitas Islam Negeri Sunan Gunung Djati, 2018. http://digilib.uinsgd.ac.id/13821/.

Ulya, Eka Sari. "Analisis Hukum Islam Terhadap Perubahan Harga Pada Tebasan Padi Yang Belum Panen Di Desa Betiring Kecamatan Brondong Kabupaten Lamongan.” Universitas Islam Negeri Sunan Ampel, 2015. http://digilib.uinsby.ac.id/2239/.

Zainal Musthofa. "Analisis Terhadap Praktik Jual Beli Istishna' Pada Produk Kerajinan Berdasarkan Fatwa Dewan Syariah Nasional No: 06/DSN-MUI/IV/2000 (Studi Kasus Di Sentra Kerajinan Kasongan Daerah Istimewa Yogyakarta)." Universitas Muhammadiyah Yogyakarta, 2017. http://repository.umy.ac.id/handle/123456789/21816. 